\title{
MICROBIOLOGICAL DIAGNOSIS OF THE SEVERE CHRONIC PERIODONTITIS
}

\author{
L. Boyanova, L. Setchanova, G. Gergova, T. Kostyanev, D. Yordanov, Chr. \\ Popova*, K. Kotsilkov*, I. Mitov \\ Department of Medical Microbiology, \\ *Department of Periodontology, Faculty of Dental Medicine, \\ Medical University of Sofia, Bulgaria
}

\begin{abstract}
In total, 14 adult patients with severe chronic periodontitis were evaluated for the presence of associated anaerobic and aerobic bacteria. Subgingival plaque specimens from three pocket depths per patient were obtained. Microaerophilic and facultative anaerobic bacteria, probably involved in the periodontitis, were isolated in six (42.9\%) patients. These were Gram negative species involving Aggregatibacter (Haemophilus) aphrophilus (14.3\%), Haemophilus parainfluenzae (7.1\%), Kingella denitrificans (7.1\%) and Moraxella osloensis $(7.1 \%)$ as well as Gram-positive species, including Arcanobacterium (Actinomyces) pyogenes (7.1\%) and Rhodococcus equi (7.1\%). Anaerobic microbiology was completed for 12 patients. Of them, suspected periodontopathogens were isolated in seven $(58.3 \%)$ patients and comprised Prevotella intermedia (in $41.7 \%$ of the patients) and Porphyromonas gingivalis (25\%) as well as Porphyromonas endodontalis (8.3\%). Tannerella forsythia was detected by PCR in half of the 12 cases. In conclusion, the presence of periodontopathogens as well as other bacterial species of possible importance should be considered in the patients with severe chronic periodontitis.
\end{abstract}

Key words: periodontitis, microbiological diagnosis, periodontal pathogens, subgingival plaque, Susceptibility testing

Periodontal diseases are serious diseases in humans and, if untreated, can cause the tooth to loosen and then to be lost. Up to $30 \%$ of the adults have been reported to have periodontitis with presence of $\geq 3$ teeth with pockets of $\geq 4 \mathrm{~mm}$ (Kumar et al., 2005). Chronic periodontitis have been considered to be chromic infections, involving anaerobic, microaerophilic and aerobic bacteria. Many putative periodontal pathogens have been extensively evaluated and involved Aggregatibacter actinomycetemcomitans, Prevotella intermedia, Tannerella forsythia, Porphyromonas gingivalis, Porphyromonas endodontalis, Treponema denticola etc. (Kumar et al., 2003; Kumar et al., 2005).

\section{AIM}

The aim of this study was to assess the incidence and susceptibility patterns of the anaerobic and aerobic bacteria as periodontopathogens as well as other bacterial species of possible importance in the patients with severe chronic periodontitis.

\section{MATERIALAND METHODS}

In total, 27 adult patients with severe chronic periodontitis were evaluated for the presence of associated anaerobic and aerobic bacteria. Of them, 22 patients were untreated and 5 were treated for the periodontitis. Anaerobic microbiology was performed to detect the growth of the suspected peiodondontopathogens such as $P$. intermedia, $P$. gingivalis and $P$. endodontalis, as well as the presence of T. forsythia by PCR. Additionally, the presence of nonintermedia pigmented Prevotella spp. (NIPPS), and Actinomyces odontolyticus (AO) spp. was evaluated.

Subgingival plaque specimens from three pocket depths per patient were obtained. The pocket depths were 3-5, 5-7 and $>7 \mathrm{~mm}$. For the first four patients, one subgingival pocket specimen per patient was taken for both aerobic and anaerobic microbiology. For the other patients, two subgingival pocket specimens per patient (one for aerobic and one for anaerobic microbiology) were taken with sterile paper-points (35Roeko). The specimens for anaerobic microbiology were placed in Stuart transport medium (BBL) or Portagerm (bio Merieux) and were sent to the laboratory within $1-2 \mathrm{~h}$.

\section{Anaerobic microbiology}

The anaerobic media used were:

1. Schaedler agar with kanamycin $100 \mathrm{mg} / 1$, vancomycin $7.5 \mathrm{mg} / 1$ and 5\% sheep blood (BBL);

2. Columbia CNA agar with $5 \%$ sheep blood (BBL), colistin $10 \mathrm{mg} / \mathrm{L}$ and nalidixic acid $10 \mathrm{mg} / \mathrm{l}(\mathrm{BBL})$, and

3. Non-selective medium for anaerobes, also suitable for growth of T. forsythia - Brucella blood agar with hemin and vitamin $\mathrm{K}$ (BBL), supplemented with yeast extract (Oxoid) $4 \mathrm{~g} / \mathrm{l}$, sodium pyruvate $1 \mathrm{~g} / \mathrm{l}$ (Applichem Germany) and $\mathrm{N}$ acetylmuramic acid (Sigma-Aldrich). NAM was 
dissolved to $10 \mathrm{mg} / \mathrm{ml}$ in distilled water, stored at $-20^{\circ} \mathrm{C}$, and added to the medium to a final concentration of $10 \mathrm{mg} / \mathrm{l}$ after autoclaving (Jousimies-Somer et al., 2002; Takemoto et al., 1997). Anaerobic media were incubated anaerobically using GasPak EZ Anaerobe Container System Sachets (BBL) at $37^{\circ} \mathrm{C}$ for up to 10 days.

The pigmented anaerobes were subcultured and tested with DMACA indol dropper (BBL).

The indol-positive strains were identified by Gram stain, colonial morphology, aerobic control, susceptibility to special potency discs, catalase, spot indol, and Crystal Anaerobe ID kit (BBL), (Jousimies-Somer et al., 2002). The special potency disks, (Rosco and Becton Dickinson), contained oxgall, kanamycin $(1000 \mu \mathrm{g})$, vancomycin $(5 \mu \mathrm{g})$, colistin $(10 \mu \mathrm{g})$ and metronidazole $(5 \mu \mathrm{g})$.

The isolated $P$. intermedia and $P$. gingivalis strains were tested for susceptibility to amoxicillin, metronidazole, clindamycin, azithromycin, tetracycline and ciprofloxacin with M.I.C.Evaluator (Oxoid, England) as well as with breakpoint susceptibility testing method (BST) as described previously (Boyanova et al., 2006). Actinomyces odontolyticus, Porphyromonas endodontalis and nonintermedia pigmented Prevotella strains (NIPPS) were additionally evaluated. The bacterial inoculum corresponded to $0.5 \mathrm{McF}$ arland standard and the final inoculum was about 105 c.f.u. per spot (CLSI-NCCLS, 2004). When no growth was observed on the plate after $48 \mathrm{~h}$ of anaerobic incubation, the isolate was considered to be susceptible to the agent. Breakpoints for resistance were amoxicillin $\geq 2 \mathrm{mg} /$ $\mathrm{L}$, metronidazole $\geq 32 \mathrm{mg} / \mathrm{L}$, clindamycin $\geq 8 \mathrm{mg} / \mathrm{L}$ (CLSINCCLS, 2004), tetracycline $>4$, ciprofloxacin $>1 \mathrm{mg} / \mathrm{L}$, respectively, and azithromycin $>2 \mathrm{mg} / \mathrm{L}$.

Beta-lactamase activity was evaluated by using nitrocefin disc test (Cefinase BBL, Becton Dickinson).

All colonies from the non-selective anaerobic medium after 10-day-anaerobic-inculation were collected in PBS $1 \mathrm{~mL}$ to perform PCR for T. forsythia. T. forsythia-specific primers, which amplify a 641-bp amplicon from the 16 rRNA gene, were used (Sharma et al., 2005), (Table 1).

Table 1. Primers for T. forsythia.

\begin{tabular}{|c|c|}
\hline Primers for T. forsythia & Size \\
\hline Tf-F 5'-GCGTATGTAACCTGCCCGCA-3', & \\
\hline Tf-R 5'-TGCTTCAGTGTCAGTTATACCT-3' & $641 \mathrm{bp}$ \\
\hline
\end{tabular}

PCR products were analyzed by agarose $(1 \%)$ gel electrophoresis and ethidium bromide staining.

\section{Aerobic microbiology}

The aerobic media used were:

For the isolation of the pathogenic species Aggregatibacter actinomycetemcomitans and Aggregatibacter (Haemophilus) aphrophilus (commonly associated with periodontal disease), we used selective medium with vancomycin, nonselective chocolate agar (GC agar with $1 \%$ haemoglobin and $1 \%$ isovitalex) and blood agar, and the agar of McConkey served as a negative control. The selective medium contains brain heart infusion агар (BHIA), to 1 liter of which are added: $5 \mathrm{~g}$ yeast extract, $1.5 \mathrm{~g}$ sodium fumarate, $1 \mathrm{~g}$ sodium formiate and $9 \mathrm{mg}$ vancomycin. The medium favors the oral species of the genus Aggregatibacter. The specimens were then incubated for $48 \mathrm{~h}$ in microaerophilic conditions. For identification of the isolates, we used BBL Crystal N/H and apiNH of bioMerieux, as well as ONP tests of PLIVA-Lachema.

The antimicrobial susceptibility testing was made by DDM (disk diffusion method) on Haemophilus test medium with antibiotic discs for the antimicrobials amoxicillin, trimetoprim/sulfamethoxazole, ceftriaxone, ciprofloxacin (Oxoid). The MIC determining was done for azithromycin and tetracycline by using E-test strips (AB Biodisk, Solna, Sweden).

\section{RESULTS}

Anaerobic microbiology was completed for the 27 patients. Of them, Gram-negative pigmented anaerobic bacteria ( $P$. intermedia, $P$. gingivalis, non-intermedia pigmented Prevotella spp. (NIPPS) and P. endodontalis, alone or in combinations) were isolated in $92.6 \%$ ( 25 of 27 patients), involving $90.9 \%$ ( 20 of 22 cases) of the untreated patients and all the five treated patients (Fig. 1). 
Table 2. Isolation of $P$. intermedia, non-intermedia pigmented Prevotella sp. (NIPPS), P. gingivalis, P. endodontalis and Actinomyces odontolyticus (AO) from patients with severe periodontitis before and after treatment.

\begin{tabular}{|c|c|c|c|c|c|}
\hline $\begin{array}{l}\text { Laboratory } \\
\text { PatientNo. }\end{array}$ & $\begin{array}{l}\text { Consecutive } \\
\text { patientNo. }\end{array}$ & Treatment & $\begin{array}{l}\text { Specimen } 1 \\
\text { pocket depth 3-5 mm }\end{array}$ & $\begin{array}{l}\text { Specimen } 2 \\
\text { pocket depth 5-7 mm }\end{array}$ & $\begin{array}{l}\text { Specimen } 3 \\
\text { pocket depth }>7 \mathrm{~mm}\end{array}$ \\
\hline 1 & 1 & Untreated & NIPPS, $\mathrm{AO}$ & Negative* & $\mathrm{AO}$ \\
\hline 21 & & Treated & P. intermedia & Negative & $\begin{array}{l}P \text { endodontalis, } \\
P . \text { intermedia }\end{array}$ \\
\hline 2 & 2 & Untreated & Negative & NIPPS & NIPPS \\
\hline 15 & & Treated & $\mathrm{AO}$ & Negative & NIPPS \\
\hline 3 & 3 & Untreated & NIPPS & NIPPS, AO & NIPPS, AO \\
\hline 18 & & Treated & $\mathrm{AO}$ & Negative & NIPPS \\
\hline 4 & 4 & Untreated & NIPPS & NIPPS & NIPPS \\
\hline 5 & 5 & Untreated & NIPPS & P. endodontalis & P. endodontalis \\
\hline 19 & & Treated & Negative & Negative & P. endodontalis \\
\hline 6 & 6 & Untreated & P. gingivalis & P. gingivalis & $\begin{array}{l}\text { P. gingivalis, } \\
\text { P. intermedia }\end{array}$ \\
\hline 22 & & Treated & P. intermedia & Negative & NIPPS \\
\hline 7 & 7 & Untreated & NIPPS & Negative & Negative \\
\hline 8 & 8 & Untreated & Negative & Negative & P. intermedia \\
\hline 9 & 9 & Untreated & P. gingivalis, NIPPS & P. gingivalis & $P$. gingivalis \\
\hline 10 & 10 & Untreated & P. intermedia & P. gingivalis & $\begin{array}{l}\text { P. intermedia, } \\
\text { P. gingivalis }\end{array}$ \\
\hline 11 & 11 & Untreated & P. intermedia & P. intermedia & P. intermedia \\
\hline 12 & 12 & Untreated & Negative & Negative & P. intermedia, $\mathrm{AO}$ \\
\hline 13 & 13 & Untreated & NIPPS, AO & $\mathrm{AO}$ & $\mathrm{AO}$ \\
\hline 14 & 14 & Untreated & NIPPS, AO & P. intermedia, NIPPS & NIPPS, AO \\
\hline 16 & 15 & Untreated & Negative & Negative & Negative \\
\hline 17 & 16 & Untreated & Negative & Negative & Negative \\
\hline 20 & 17 & Untreated & NIPPS & Negative & Negative \\
\hline 23 & 18 & Untreated & $\mathrm{AO}$ & P. intermedia, $\mathrm{AO}$ & $\begin{array}{l}P . \text { intermedia, } \\
P \text {. gingivalis }\end{array}$ \\
\hline 24 & 19 & Untreated & P. gingivalis & Negative & P. gingivalis \\
\hline 25 & 20 & Untreated & Negative & Negative & NIPPS \\
\hline 26 & 21 & Untreated & P. gingivalis & P. gingivalis & P. gingivalis \\
\hline 27 & 22 & Untreated & $\begin{array}{l}\text { P. intermedia, } \\
\text { P. gingivalis, } \mathrm{AO}\end{array}$ & $\begin{array}{l}\text { P. intermedia, } \\
\text { P. gingivalis, } \mathrm{AO}\end{array}$ & $\begin{array}{l}\text { P. intermedia, } \\
\text { P. gingivalis, } \mathrm{AO}\end{array}$ \\
\hline
\end{tabular}

NIPPS- Non-intermedia pigmented Prevotella sp., AO- Actinomyces odontolyticus

${ }^{* *}$ negative for $P$. intermedia, $P$. gingivalis and $P$. endodontalis.

P. intermedia was found in $37.0 \%$ (10 of 27 cases) of all patients, including $36.4 \%$ ( 8 of 22 ) untreated patients and two of five treated patients. P. gingivalis was detected in $25.9 \%$ ( 7 of 27) of all patients, including $31.8 \%$ (7 of 22 ) of the untreated subjects and in no specimen from treated patients. P. endodontalis was isolated from $11.1 \%$ (3 of 27 cases) of all patients, including $4.5 \%$ ( 1 of 22 ) of the specimens from untreated patients and two of the five specimens from treated patients.

Both $P$. intermedia and $P$. gingivalis/P. endodontalis were present in the specimens from five (four untreated and one treated) patients.

In the 22 untreated patients, $P$. intermedia and $P$.
gingivalis/P. endodontalis, alone or in combinations, were found in $31.8 \%$ (7 of 22 specimens) of the specimens from pocket depth 3-5 mm, 40.9\% (9 of 22) of those from pocket depth $5-7 \mathrm{~mm}$ and in $50 \%$ (11 of 22) of those from pocket depth $>7 \mathrm{~mm}$ (Table 4).

In untreated patients, $A$. odontolyticus was detected in five specimens from pocket depth 3-5 $\mathrm{mm}$, four specimens from pocket depth 5-7 $\mathrm{mm}$ and six specimens from pocket depth $>7 \mathrm{~mm}$. In treated patients, however, A. odontolyticus was found only in two specimens from pocket depth 3-5 $\mathrm{mm}$.

In untreated patients, NIPPS were found in nine specimens from pocket depth 3-5 $\mathrm{mm}$, four specimens from 
pocket depth 5-7 $\mathrm{mm}$ and five specimens from pocket depth $>7 \mathrm{~mm}$.

T. forsythia was detected by PCR in $44.4 \%$ ( 8 of 18 cases) of the patients evaluated, involving $50 \%$ ( 8 of 16 ) of the untreated patients and none of the two treated patients. Within the untreated patients, T. forsythia positive were $37.5 \%$ (6 of 16 cases) of the specimens from pocket depth 3-5 mm, 50\% (8 of 16) of those from pocket depth 5-7 $\mathrm{mm}$ and in $37.5 \%$ (6 of 16 cases) of those from pocket depth $>7 \mathrm{~mm}$

Susceptibility testing was performed with 19 strains (15 strains from untreated patients and four strains from treated patients) of the pigmented anaerobic periodontopathogens, isolated from 11 untreated and 3 treated patients: P. intermedia (9 strains), P. gingivalis (7 strains) and $P$. endodontalis (3 strains), (Fig. 2).

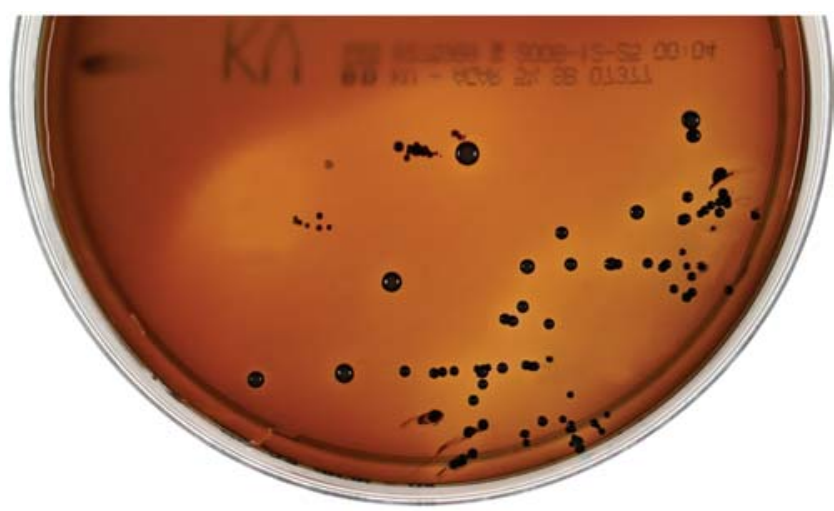

Fig. 1. Growth of Prevotella intermedia on Schaedler agar with kanamycin, vancomycin and 5\% sheep blood (BBL).

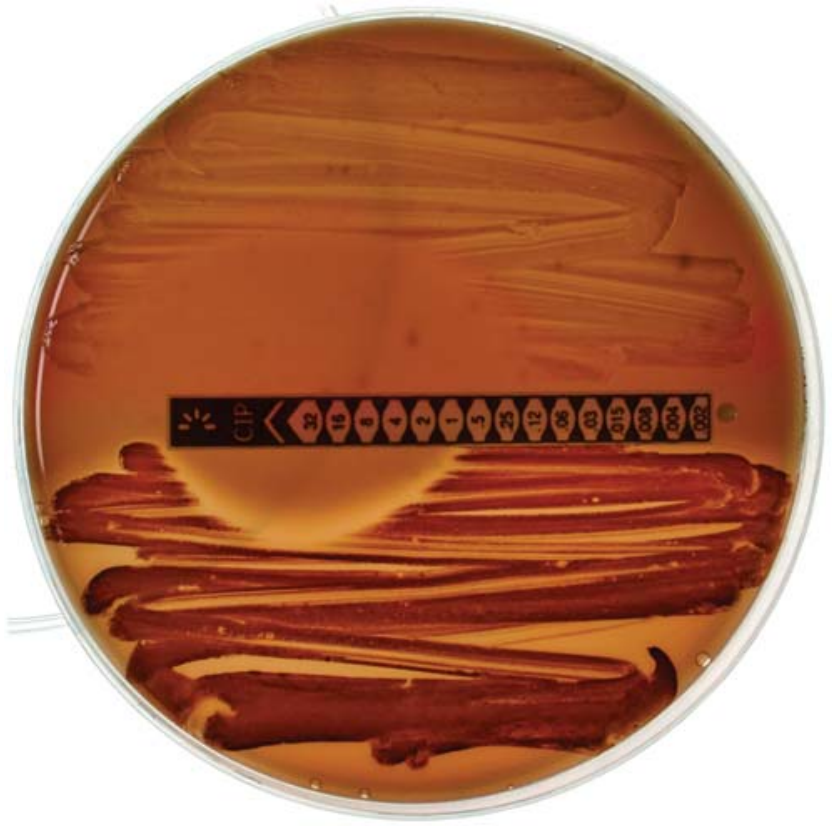

Fig. 2. Susceptibility testing of $P$. intermedia and $P$. gingivalis by M.I.C.Evaluator (Oxoid, England)

Thirteen $(86.7 \%)$ of the 15 strains from untreated patients were susceptible to amoxicillin (MICs, $\leq 0.5 \mathrm{mg} / \mathrm{L}$ ), while amoxicillin resistance was found in one $P$. intermedia strain (amoxicillin MIC, $16 \mathrm{mg} / \mathrm{L}$ ) and one P. gingivalis strain (MIC, $2 \mathrm{mg} / \mathrm{L}$ ).

All the 15 strains from untreated patients were susceptible to metronidazole (MICs, 0.06-2 mg/L), clindamycin (MICs, $0.016-0.38 \mathrm{mg} / \mathrm{L}$ ) and azithromycin (MICs, $0.023-1 \mathrm{mg} / \mathrm{L}$ ). Six (40.0\%) strains from the untreated 15 patients were resistant to tetracycline (MICs, $>4 \mathrm{mg} / \mathrm{L}$ ), (Table 1). Three $(21.4 \%)$ of the 14 strains tested for susceptibility to ciprofloxacin, was resistant to the agent (MIC, $32 \mathrm{mg} / \mathrm{L}$ ).

It is of note that two of the four strains of the pigmented anaerobic periodontopathogens ( $P$. intermedia, $P$. gingivalis and $P$. endodontalis) from the three treated patients, were resistant to amoxicillin and were betalactamase positive. Both resistant strains belonged to the species $P$. intermedia. One $P$. intermedia strain from a treated patient acquired a secondary resistance to amoxicillin (the strain being susceptible to the agent before treatment and resistant after treatment).

The strains from the treated patients were susceptible to metronidazole (MICs, $\leq 8 \mathrm{mg} / \mathrm{L}$ ), clindamycin (MICs, $\leq 2$ $\mathrm{mg} / \mathrm{L}$ ), azithromycin (MICs, $\leq 2 \mathrm{mg} / \mathrm{L}$ ) and ciprofloxacin (MICs, $\leq 1 \mathrm{mg} / \mathrm{L}$ ). One patient' strain, which was tetracycline resistant (MIC, $8 \mathrm{mg} / \mathrm{L}$ ), remained resistant after treatment with the same MIC concentration.

\section{DISCUSSION}

Boutaga et al. (2007) have reported the real-time polymerase chain reaction (PCR) to be a very sensitive technique to detect bacterial periodontopathogens. Probably, the relatively low detection rate of Porphyromonas spp. (36.4\%, 8 of 22 cases) in the untreated patients in the present study could be explained by the use of culture instead of PCR-based method as well as by the use of one specimen per patient for both aerobic and anaerobic microbiology laboratories for the first four patients (Table 3). 
Table 3. Prevalence of $P$. intermedia, $P$. gingivalis, $P$. endodontalis and $T$. forsyrthia in untreated patients with periodontitis acc. to several studies.

\begin{tabular}{|c|c|c|c|c|c|c|}
\hline $\begin{array}{l}\text { Prevalence } \\
(\%) \text { Acc. to }\end{array}$ & $\begin{array}{l}\text { No. of } \\
\text { patients }\end{array}$ & Method & $\begin{array}{c}P . \\
\text { intermedia }\end{array}$ & $\begin{array}{c}P \\
\text { gingivalis }\end{array}$ & $\begin{array}{c}P . \\
\text { endodontalis }\end{array}$ & $\begin{array}{c}T . \\
\text { forsyrthia }\end{array}$ \\
\hline $\begin{array}{l}\text { Colombo et al., } \\
2006\end{array}$ & 49 & $\begin{array}{c}\text { Checkerboard DNA-DNA } \\
\text { hybridization method }\end{array}$ & 37.0 & 42.0 & NA & 26.0 \\
\hline $\begin{array}{l}\text { Ready et al., } \\
2008\end{array}$ & 107 & PCR & NA & 78.0 & NA & 81.0 \\
\hline $\begin{array}{l}\text { Rocas \& Siqueira, } \\
2008\end{array}$ & $\mathrm{NA}^{\#}$ & $\begin{array}{c}\text { Reverse-capture checkerboard } \\
\text { hybridization assay }\end{array}$ & NA & NA & $56.0^{\pi}$ & 19.0 \\
\hline $\begin{array}{l}\text { Romano et al., } \\
2007\end{array}$ & 21 & PCR & 55.5 & 61.1 & NA & 72.2 \\
\hline $\begin{array}{l}\text { Salari \& } \\
\text { Kadkhoda, } 2004\end{array}$ & & Culture & 10.5 & 21.9 & NA & NA \\
\hline $\begin{array}{l}\text { Yoshida et al., } \\
2005\end{array}$ & 10 & $\begin{array}{c}\text { Loop-mediated isothermal } \\
\text { amplification method }\end{array}$ & NA & 60.0 & NA & 50.0 \\
\hline $\begin{array}{l}\text { Present study } \\
\text { (untreated } \\
\text { patients) }\end{array}$ & $22^{*}$ & $\begin{array}{l}\text { Culture for } P \text {. intermedia, } P \text {. } \\
\text { gingivalis, and } P \text {. endodontalis, } \\
\text { and PCR for } T \text {. forsyrthia }\end{array}$ & 36.4 & 31.8 & 4.5 & 50.0 \\
\hline
\end{tabular}

NA - non-available, *- 16 patients were tested by PCR for T. forsythia. ${ }^{*}-43$ teeth specimens, ${ }^{\top}$ - for bacteria present at levels $>10^{5}$

The incidence of $P$. intermedia in the present study was similar to those (10.5-55.5\%) reported in the literature but was higher than that in the culture-based study of Salari \& Kadkhoda (2004). In the present study, however, the detection of both $P$. gingivalis and $P$. endodontalis was lower than that by PCR-based methods but was higher than that performed with culture by Salari \& Kadkhoda (2004).

Both $P$. intermedia and $P$. gingivalis/P. endodontalis per specimen were found only in one specimen from pocket depth 3-5 mm, one specimen from pocket depth 5-7 $\mathrm{mm}$ and in more (five) specimens from pocket depth $>7 \mathrm{~mm}$. The Gram-negative pigmented anaerobic periodontopathogens

from untreated patients exhibited similar antibacterial susceptibility patterns to those in the study of Kulik et al. (2008), except for the higher resistance $(40.0 \%)$ to tetracycline in the present study compared to $0-12.6 \%$ in the study of Kulik et al. (2008).

The acquisition of amoxicillin resistance in one $P$. intermedia strain, which was amoxicillin susceptible before treatment, is of clinical significance.

It is important that in untreated patients, more $P$. intermedia, $P$. gingivalis and $P$. endodontalis isolates were cultured from specimens of pocket depth $>7 \mathrm{~mm}$ than in those with other depths (Table 4).

Table 4. Distribution of anaerobic periodontopathogens according to the depth of the pocket.

\begin{tabular}{|l|c|c|c|c|c|c|}
\hline Anaerobic species & \multicolumn{3}{|c|}{ Untreated patients (no.=22** } & \multicolumn{3}{c|}{ Treated patients (no. $=\mathbf{5})^{*}$} \\
\hline Pocket depth & $3-5 \mathrm{~mm}$ & $5-7 \mathrm{~mm}$ & $>7 \mathrm{~mm}$ & $3-5 \mathrm{~mm}$ & $5-7 \mathrm{~mm}$ & $>7 \mathrm{~mm}$ \\
\hline P. intermedia & 3 & 4 & 7 & 2 & 0 & 1 \\
\hline P. gingivalis & 5 & 5 & 7 & 0 & 0 & 0 \\
\hline P. endodontalis & 0 & 1 & 2 & 0 & 0 & 1 \\
\hline T. forsythia * & 6 & 8 & 6 & 0 & 0 & 0 \\
\hline NIPPS & 9 & 4 & 5 & 0 & 0 & 3 \\
\hline A. odontolyticus & 5 & 4 & 6 & 2 & 0 & 0 \\
\hline
\end{tabular}

* Only 16 untreated and two treated patients were evaluated for T. forsythia by PCR. 


\section{CONCLUSION}

In conclusion, the presence of periodontopathogens as well as other bacterial species of possible importance should be considered in the patients with severe chronic periodontitis. The specimens with pocket depth $>7 \mathrm{~mm}$ were associated with higher rate of positive pigmented anaerobic periodontopathogenic bacteria and, in some cases, with more frequent presence of two pigmented anaerobic isolates per specimen. Half of the untreated patients harbored $T$. forsythia. The pigmented anaerobic periodontopathogens from untreated patients had a high susceptibility rate to amoxicillin, metronidazole, clindamycin, and azithromycin but relatively low susceptibility rate to tetracycline. Out of all the isolated aerobic species, A. aphrophilus was the most significant one. It can be considered as a part of the causative agents of periodontal disease. The isolates had a high susceptibility rate to amoxicillin, azithromycin, ceftriaxone, tetracycline and ciprofloxacin.

\section{REFERENCES:}

1. Boyanova, L., R. Kolarov, G. Gergova, E. Deliverska, J. Madjarov, M. Marinov, I. Mitov. Anaerobic bacteria in 118 patients with deep-space head and neck infections from the University Hospital of Maxillo-Facial Surgery, Sofia, Bulgaria. J. Med. Microbiol. 2006, 55 (Pt 9): 1285-1289.

2. Boutaga K., Savelkoul P. H., Winkel E. G., van Winkelhoff A. J. Comparison of subgingival bacterial sampling with oral lavage for detection and quantification of periodontal pathogens by real-time polymerase chain reaction. J Periodontol. 2007; 78(1): 79-86.

3. CLSI- National Committee for Clinical Laboratory Standards. Methods for antimicrobial susceptibility testing of anaerobic bacteria. 6th ed. Approved standard M11-A6. 2004. Villanova, PA: NCCLS.

4. Colombo A. V., Silva C. M., Haffajee A., Colombo A. P. Identification of oral bacteria associated with crevicular epithelial cells from chronic periodontitis lesions. J Med Microbiol. 2006; 55(Pt 5):609-615.

5. Jousimies-Somer, H., Summanen, P., Citron, D., Baron, E.J., Wexler, H.M. \& Finegold, S.M., eds. (2002). Wadsworth
Anaerobic Bacteriology Manual. Belmont, $\mathrm{Ca}$ : Star Publishing.

6. Kulik EM, Lenkeit K, Chenaux S, Meyer J. Antimicrobial susceptibility of periodontopathogenic bacteria. Antimicrob Chemother. 2008; 61(5):1087-91.

7. Kumar P. S., Griffen A. L., Barton J. A., Paster B. J., Moeschberger M. L., Leys E. J. New bacterial species associated with chronic periodontitis. J Dent Res. 2003 May; 82(5):338-44.

8. Kumar P. S., Griffen A. L., Moeschberger M. L., Leys E. J. Identification of candidate periodontal pathogens and beneficial species by quantitative $16 \mathrm{~S}$ Clonal Analysis. J Clin Microbiol. 2005; 43: 3944 - 3955.

9. Ready D., D’Aiuto F., Spratt D. A., Suvan J., Tonetti M. S., Wilson M. Disease severity associated with presence in subgingival plaque of Porphyromonas gingivalis, Aggregatibacter actinomycetemcomitans, and Tannerella forsythia, singly or in combination, as detected by nested multiplex PCR. J Clin Microbiol. 2008; 46: 3380 - 3383.

10. Rфзаs I. N., Siqueira J. F. Jr. Root canal microbiota of teeth with chronic apical periodontitis. J Clin Microbiol.
2008; 46(11):3599-3606.

11. Romano F., Barbui A., Aimetti M. Periodontal pathogens in periodontal pockets and in carotid atheromatous plaques. Minerva Stomatol, 2007; 56(4): 169-79.

12. Salari M. H., Z. Kadkhoda Z. Rate of cultivable subgingival periodontopathogenic bacteria in chronic periodontitis. J Oral Sci. 2004; 46(3): 157-161.

13. Sharma A., Inagaki S., Honma K., Sfintescu C., Baker P.J., Evans R.T. Tannerella forsythia-induced alveolar bone loss in mice involves leucine-rich-repeat BspA protein. J Dent Res. 2005; 84(5):462-7

14. Takemoto T., Kurihara H., Dahlen G. Characterization of Bacteroides forsythus isolates. Comparison of growth media. J Clin Microbiol. 1997; 35 (6): 1378-1381

15. Yoshida A., Nagashima S., Ansai T., Tachibana M., Kato H., Watari H., Notomi T., Takehara T. Loop-mediated isothermal amplification method for rapid detection of the periodontopathic bacteria Porphyromonas gingivalis, Tannerella forsythia, and Treponema denticola. J Clin Microbiol. 2005; 43: 2418 - 2424.

\author{
Address for correspondence: \\ Dr K. Kotsilkov \\ Department of Periodontology, Faculty of Dental Medicine, \\ Medical University of Sofia, \\ 1, Georgi Sofiiski Str., Sofia, Bulgaria \\ Mobile: +359898781299 \\ E-mail: kotsilkov@mail.bg
}

